\title{
ROLE OF LAPAROSCOPY IN MANAGEMENT OF ABDOMINAL TRAUMA
}

\author{
By
Haroun A. Allam, Ibrahim A. Ibrahim, Mohamed M. Tag El-Din and Ahmed A. Mahmoud \\ Department of General Surgery, Faculty of Medicine, Al-Azhar University \\ Corresponding author: Ahmed A. Mahmoud, Mobile: 01026460730, \\ E-mail: moramido286@gmail.com
}

\begin{abstract}
Background: Abdominal trauma affects $10 \%$ to $15 \%$ of injured patients. Although significant intraabdominal injury is relatively infrequent, the consequences of missed or delayed diagnosis can be significant. Therefore, accurate and timely diagnosis of injuries is essential.

Objective: To study the feasibility, the advantages, and the disadvantages of laparoscopy in diagnosis and treatment of abdominal trauma.

Patients and Methods: This randomized prospective study included 50 patients with abdominal trauma of any type whether blunt or penetrating, road traffic accident (RTA) or falling from height, stab or gunshot. Mean age was of patients was $29.26 \pm 8.55$ years old and mean BMI was $26.36 \pm 3.12$. Ninety eight percent of them were males and $2 \%$ of them were females.

Results: The intraoperative bleeding occurred in one patient (2\%). Female patient presented after lower abdominal stab wound (BP 90/50 -HB 8 -HR 120). After resuscitation diagnostic laparoscopy found uncontrolled bleeding from uterine tear. Post-operative complications occurred in $8 \%$ post laparotomy and $14 \%$ post laparoscopy. Patients underwent laparotomy delayed in return to daily activity (8-9 days) and to work (12-24 days) due to time of operation, length of incision and occurrence of complications and depended on age, BMI, power of healing and intraoperative technique. In our experience, the use of laparoscopy as a diagnostic and therapeutic tool led to avoidance of an open surgery in more than $64 \%$ of patients. Negative and non-therapeutic laparoscopies were performed in 7 patients and therapeutic laparoscopy was performed in 25 patients: 8 patients hand assisted splenectomy, 5 patients needed repair of liver tears, 3 patients needed diaphragmatic tear repair, 7 patients needed primary repair for bowel and 2 patients needed stomach repair. However, conversion to laparotomy was needed in 18 cases more than 30\%. Multiple organ injuries occurred in $16 \%$, colostomy for descending and sigmoid colonic tears $(10 \%)$, resection anastomosis for multiple small bowel injuries (2\%), repair for uterine injuries $(2 \%)$.
\end{abstract}

Conclusion: The keys to successfully diagnosing and treating significant intra-abdominal injuries laparoscopically include a systemic exploration to avoid missed injuries using appropriate changes in position of the patient, careful planning of port placement. Minimally invasive surgery has become a useful tool in the management of trauma. Laparoscopy can detect and repair injuries to the hollow viscus and diaphragm and exclude the risks of non-therapeutic laparotomy. Further advantages are reduced morbidity, shortened hospital stay, and lower cost. In the future, there may be exciting advancements for this field of surgery through innovative developments.

Key words: laparoscopy, Management abdominal trauma. 


\section{INTRODUCTION}

Intra-abdominal trauma affects $10 \%$ to $15 \%$ from whole types of trauma. Although significant intra-abdominal injury relatively infrequent, the consequences of missed or delayed diagnosis can be significant. Therefore, accurate and timely diagnosis of injuries is essential. The initial history and physical examination are of paramount importance. Information regarding the mechanism of injury and state of patient before arriving in the emergency department can be very helpful in assessment and management of the patient (Neal et al., 2009).

Mechanisms of injuries may be penetrating or blunt. The most common cause of mortality in abdominal trauma is secondary to delayed resuscitation or excessive hemorrhage with inadequate volume resuscitation or Intra-abdominal organ injury and rupture or perforation precipitates gastrointestinal content spillage into the peritoneal cavity, frequently leading to peritonitis and delayed mortality from severe sepsis (Mackersie, 2010).

Despite the high prevalence of patients with abdominal trauma. Physical examination may not be accurate because patients may have altered mental status or distracting injuries. Diagnostic peritoneal lavage was introduced as a diagnostic modality to identify hemoperitoneum but it is invasive method and its role has been almost entirely eliminated because there has been increased reliance on abdominal computed tomography. Focused Assessment with Sonography in trauma and has also been added to the diagnostic algorithm for patients with abdominal trauma (Deunk et al., 2010).
The burden of major trauma, predominantly blunt in nature, continues to rise in the most of the countries. More often the young are affected with lifelong debilitating consequences. Minimally invasive technique, such as laparoscope procedures, have become standard for the treatment of many surgical conditions, being able to minimize the impact of the surgery, to reduce postoperative pain, time to recover and to improve cosmetic outcomes (Bendinelli and Balogh, 2012).

In laparoscopic procedure, the relative morbidity and mortality, complication rates, and missed injury rates are low and comparable with open approaches. Additionally, a wide variety of intraabdominal pathology can be addressed laparoscopically including injuries to the bowel, diaphragm, liver, spleen and pancreas. Guidelines developed by the Eastern Association for the Surgery of Trauma Practice Management Guidelines Committee recommend selective nonoperative management in penetrating abdominal trauma and that routine laparotomy is not indicated in hemodynamically stable patients with abdominal stab wounds without signs of peritonitis or diffuse abdominal pain and in patients suffering tangential gunshot wounds without peritonitis (Como et al., 2010).

With increasing incorporation of endoscopic surgery into general practice, there will be a solid place for the laparoscopic approach to diagnose and therapeutic modality in abdominal trauma. It may be particularly beneficial for hemodynamically stable patients that sustained a focal abdominal trauma. We expect that this approach will lead to a 
decline in non-therapeutic laparotomies, and its associated complications (Ball et al., 2009).

The aim of the work was to study the feasibility, the advantages and the disadvantages of laparoscopy in diagnosis and treatment of abdominal trauma.

\section{PATIENTS AND METHODS}

Our study was randomized prospective study. It included 50 patients with abdominal trauma of any type whether blunt or penetrating, RTA or falling from height, stab or gunshot. Patients were selected from those attending the general surgery department of Ministry of Health hospitals and Al Houssin university hospital, during period from 1/1/2017 till $1 / 1 / 2019$. The study included vitally stable patients, patients with equivocal abdominal signs, concomitant injuries and GCS more than 13.

Unstable patients required urgent laparotomy, pregnant females, severe head injuries, patient with multiple previous abdominal operations, limited cardiovascular reserve and patients with severe chest restriction were excluded from the study.

In order to study the sensitivity and specificity in diagnosis and evaluation of abdominal trauma by the use of ultrasonography, CT and abdominal laparoscopy and comparing accuracy of diagnosis of them with the final diagnosis.

Patients were subjected to history taking, general examination and investigational laboratory and radiology.

\section{Statistical analysis:}

Data were coded and entered using the statistical package SPSS (Statistical Package for the Social Sciences) version 25. Data were summarized using mean, standard deviation, minimum and maximum in quantitative data and using frequency (count) and relative frequency (percentage) for categorical data. Comparisons between quantitative variables were done using the nonparametric Mann-Whitney test. For comparing categorical data, Chi square ( $\chi 2)$ test was performed. Exact test was used instead when the expected frequency was less than 5. ROC curve was constructed with area under curve analysis performed to detect best cutoff value of ADC and SIR for detection of malignancy. P-values less than 0.05 were considered statistically significant. 


\section{RESULTS}

The preoperative assessment of patients showed that the mean systolic blood pressure $107.00 \pm 12.33 \mathrm{mmHg}$, mean diastolic blood pressure 68.00 \pm 7.46

$\mathrm{mmHg}$, mean heart rate $98.56 \pm 15.73$ beats/minute and mean hemoglobin was $9.50 \pm 1.25 \mathrm{~g} / \mathrm{dl}$ (Table 1).

Table (1): Patients demographic, vital data and hemoglobin

\begin{tabular}{|c|c|c|c|}
\hline \multicolumn{2}{|c|}{ Parameter Count } & Mean/number & Min-max/percent \\
\hline \multicolumn{2}{|c|}{ Age (Years) } & 29.26 & $(15-62)$ \\
\hline \multicolumn{2}{|c|}{ BMI } & 26.36 & $(21-35)$ \\
\hline \multirow{2}{*}{ Gender } & Male & 49 & $98 \%$ \\
\hline & Female & 1 & $2 \%$ \\
\hline \multicolumn{2}{|c|}{ Initial Systolic BP (mmHg) } & 107.00 & $(80-140)$ \\
\hline \multicolumn{2}{|c|}{ Initial Diastolic BP (mmHg) } & 68.00 & $(40-90)$ \\
\hline \multicolumn{2}{|c|}{ Initial Heart rate (Beat/Minute) } & 98.56 & $(70-160)$ \\
\hline \multicolumn{2}{|c|}{ Hemoglobin $(\mathrm{g} / \mathrm{dl})$} & 9.50 & $(6-13)$ \\
\hline
\end{tabular}

Those patients exposed to abdominal trauma (20\% of them) were RTA, $60 \%$ gunshot, $14 \%$ stab wound, and $6 \%$ explosion. The indications of diagnostic laparoscopy in 39 patients $(78 \%)$ were radiological findings, 9 patients (18\%) penetrating wounds (gunshot and stab) to abdominal wall, while 2 patients (4\%) presented after RTA. With negative radiology under observation noticed decrease hemoglobin level $(7 \mathrm{~g} / \mathrm{dl})$ and hypotension $(90 / 60 \quad \mathrm{mmHg}) \quad$ with tachycardia (100-110 beats/min) (Table 2).

Table (2): Mechanism of trauma and indications of diagnostic laparoscopy

\begin{tabular}{|l|c|c|}
\hline Parameter Count & Frequency & Percent \\
\hline RTA & 10 & $20 \%$ \\
\hline Gun Shoot & 30 & $60 \%$ \\
\hline Stab Wound & 7 & $14 \%$ \\
\hline Explosion & 3 & $6 \%$ \\
\hline Radiological & 39 & $78 \%$ \\
\hline Gun Shoot & 3 & $6 \%$ \\
\hline Gun shoot and Bp & 1 & $2 \%$ \\
\hline Gun shoot, Hb and HR & 4 & $8 \%$ \\
\hline Stab Wound & 1 & $2 \%$ \\
\hline HR and Hb & 2 & $4 \%$ \\
\hline
\end{tabular}

The mean operative time was $71.40 \pm$ 29.34 minutes. The diagnostic laparoscopy found that $8 \%$ of patients were negative, $6 \%$ were non-therapeutic,
$34 \%$ were therapeutic, $16 \%$ were minilaparotomy and $36 \%$ were laparotomy (Table 3). 
Table (3): Operative time

\begin{tabular}{|l|c|c|c|}
\hline Procedure & Total & Laparotomy & $\begin{array}{c}\text { Laparoscopy } \\
\text { (Diagnostic \& } \\
\text { therapeutic) }\end{array}$ \\
\hline $\begin{array}{l}\text { Operative time } \\
\text { (minutes) }\end{array}$ & $71.40(30-150)$ & $95.29(60-150)$ & $59.09(30-120)$ \\
\hline
\end{tabular}

Therapeutic procedure done totally laparoscopic in 17 cases. 3 patients with diaphragmatic tear repaired laparoscopally by intracorporal suturing using silk zero. 5 patients with liver tear control bleeding by cautery or topical homeostasis using surgicell and hepatorrhaphy by vicreyl zero. Application of Ligaclips to control mesenteric bleeding. Stapling or suturing of small intestinal wounds if single small tear. Stapling or suturing of stomach tear. Stapling or suturing Primary repair of ascending and transverse colon if single small non soiling tear (Table 4).

Table (4): Findings of Diagnostic Laparoscopy

\begin{tabular}{|l|c|c|c|c|}
\hline \multicolumn{1}{|c|}{ Count } & Frequency & Percent & $\begin{array}{c}\text { Blood } \\
\text { transfusion } \\
\text { Parameter }\end{array}$ & $\begin{array}{c}\text { Plasma } \\
\text { transfusion } \\
(\text { PT })\end{array}$ \\
\hline Negative & 4 & $8 \%$ & 1 & 3 \\
\hline Non-therapeutic & 3 & $6 \%$ & 1 & 2 \\
\hline Therapeutic & 17 & $34 \%$ & 3 & 14 \\
\hline Mini-Laparotomy & 8 & $16 \%$ & 4 & 4 \\
\hline Laparotomy & 18 & $36 \%$ & 1 & 17 \\
\hline
\end{tabular}

Conversion from laparoscopy to laparotomy after identifying the pathology done in 18 cases due to multiple organ injuries $(10 \mathrm{pt})$, fecal peritonitis due to descending and sigmoid tears $(4 \mathrm{pt})$, multiple small bowel injuries needed resection anastomosis (1pt) and retroperitoneal organ injuries $(2 \mathrm{pt})$ as kidney and urinary bladder. Female patient with uterine tear undergoes laparotomy for repair (Table 5). 
HAROUN A. ALLAM et al.,

Table (5): Therapeutic procedures, and mini-laparotomy (hand-assessed), laparotomy

\begin{tabular}{|c|c|c|c|}
\hline \multicolumn{2}{|c|}{$\begin{array}{ll}\text { Parameter } & \text { Findings } \\
\end{array}$} & $\begin{array}{c}\text { Number } \\
(\%)\end{array}$ & Technique \\
\hline \multicolumn{2}{|c|}{ Diaphragm } & $3(17.6 \%)$ & Repair \\
\hline \multicolumn{2}{|l|}{ Stomach } & $1(5.9 \%)$ & Repair \\
\hline \multicolumn{2}{|l|}{ Liver } & $5(29.4 \%)$ & Repair \\
\hline \multirow{2}{*}{$\begin{array}{l}\text { Small } \\
\text { Intestine }\end{array}$} & Jejunum & $2(11.8 \%)$ & Repair \\
\hline & Mesentery & $1(5.9 \%)$ & Clip ligation \\
\hline \multirow{3}{*}{$\begin{array}{l}\text { Large } \\
\text { Intestine }\end{array}$} & Ascending & $1(5.9 \%)$ & Primary repair \\
\hline & Transverse & $2(11.8 \%)$ & Repair \\
\hline & Splenic flexure & $1(5.9 \%)$ & Primary repair \\
\hline \multicolumn{2}{|c|}{ Stomach \& gallbladder } & $1(5.9 \%)$ & Cholecystectomy \& pyloric repair \\
\hline \multicolumn{2}{|l|}{ Total } & & $100 \%)$ \\
\hline \multicolumn{2}{|l|}{ Spleen } & $7(87.5 \%)$ & hand assist splenectomy \\
\hline \multicolumn{2}{|c|}{ Diaphragm \& spleen } & $1(12.5 \%)$ & Repair \& hand assist splenectomy \\
\hline \multicolumn{2}{|c|}{ Total } & & $8(100 \%)$ \\
\hline \multicolumn{2}{|l|}{ Uterus } & $1(5.6 \%)$ & Laparotomy \& repair \\
\hline \multirow{3}{*}{$\begin{array}{l}\text { Small \& } \\
\text { large } \\
\text { Intestine }\end{array}$} & Multiple small intestine & $1(5.6 \%)$ & $\begin{array}{c}\text { Laparotomy, Resection \& } \\
\text { anastomosis }\end{array}$ \\
\hline & Descending colon & $2(11.1 \%)$ & Laparotomy \& colostomy \\
\hline & Sigmoid colon & $2(11.1 \%)$ & Laparotomy \& colostomy \\
\hline \multicolumn{2}{|c|}{$\begin{array}{l}\text { Diaphragm \& Large Intestine (splenic } \\
\text { Flexure) }\end{array}$} & $2(11.1 \%)$ & Repair, laparotomy \& colostomy \\
\hline \multicolumn{2}{|c|}{$\begin{array}{l}\text { Large intestine (rectum), ureter } \& \\
\text { urinary bladder }\end{array}$} & $1(5.6 \%)$ & $\begin{array}{c}\text { Laparotomy, repair \& ureter } \\
\text { reimplantation }\end{array}$ \\
\hline \multicolumn{2}{|c|}{$\begin{array}{l}\text { Large intestine (sigmoid) } \& \\
\text { retroperitoneal hematoma }\end{array}$} & $1(5.6 \%)$ & Laparotomy \& colostomy \\
\hline \multicolumn{2}{|c|}{ Diaphragm, liver \& kidney } & $1(5.6 \%)$ & Laparotomy, repair \& nephrectomy \\
\hline \multicolumn{2}{|c|}{$\begin{array}{l}\text { Small intestine (ileum), large intestine } \\
\text { (caecum) \& retroperitoneal hematoma }\end{array}$} & $1(5.6 \%)$ & $\begin{array}{c}\text { Laparotomy, repair \& right } \\
\text { hemicolectomy }\end{array}$ \\
\hline \multicolumn{2}{|c|}{$\begin{array}{l}\text { Small intestine (ileum) \& large } \\
\text { intestine (ascending) }\end{array}$} & $1(5.6 \%)$ & $\begin{array}{l}\text { Laparotomy, hemicolectomy\&ilio- } \\
\text { colic anastomosis }\end{array}$ \\
\hline \multicolumn{2}{|c|}{$\begin{array}{l}\text { Small intestine (ileum), large intestine } \\
\text { (sigmoid), urinary bladder \& } \\
\text { retroperitoneal hematoma }\end{array}$} & $1(5.6 \%)$ & $\begin{array}{l}\text { Laparotomy, primary repair \& } \\
\text { sigmoidal colostomy }\end{array}$ \\
\hline \multicolumn{2}{|c|}{$\begin{array}{l}\text { Small intestine (jejunum) and large } \\
\text { intestine (multiple) }\end{array}$} & $1(5.6 \%)$ & $\begin{array}{c}\text { Laparotomy, jejunal repair and } 2 \\
\text { barrel colostomy }\end{array}$ \\
\hline \multicolumn{2}{|c|}{$\begin{array}{l}\text { Stomach, liver, Small intestine (ileum) } \\
\text { \& large intestine (transverse) }\end{array}$} & $1(5.6 \%)$ & Laparotomy \& repair \\
\hline \multicolumn{2}{|l|}{ Total } & & $18(100 \%)$ \\
\hline
\end{tabular}

The laparoscopic technique depends on the findings. Hand assisted splenectomy in splenic tears (14\%), repair of liver tears $(10 \%)$, primary repair of small bowel $(8 \%)$, while $(2 \%)$ need laparotomy for resection anastomosis in multiple small bowel injuries, diagnostic only with no findings in $(8 \%)$, primary repair in ascending and transverse colon (8\%), primary repair of diaphragm (6\%).The intraoperative bleeding occurred in one patient $(2 \%)$. Female patient presented after lower abdominal stab wound (BP 90/50 -Hb 8 -HR 120) after resuscitation diagnostic laparoscopy find uncontrolled bleeding from uterine tear. Conversion to laparotomy and control bleeding (Table 6). 
Table (6): Findings and technique

\begin{tabular}{|c|c|c|c|}
\hline \multicolumn{2}{|l|}{ Parameters } & $\begin{array}{c}\text { Number } \\
(\%)\end{array}$ & Technique \\
\hline \multicolumn{2}{|l|}{ Negative } & $4(8 \%)$ & Diagnostic \\
\hline \multicolumn{2}{|l|}{ Collection } & $2(4 \%)$ & Suction \\
\hline \multicolumn{2}{|l|}{ Diaphragm } & $3(6 \%)$ & Repair \\
\hline \multicolumn{2}{|l|}{ Stomach } & $1(2 \%)$ & Repair \\
\hline \multicolumn{2}{|l|}{ Liver } & $5(10 \%)$ & Repair \\
\hline \multicolumn{2}{|l|}{ Spleen } & $7(14 \%)$ & hand assist splenectomy \\
\hline \multicolumn{2}{|l|}{ Uterus } & $1(2 \%)$ & Laparotomy \& repair \\
\hline \multirow{3}{*}{ Small Intestine } & Jejunum & $4(8 \%)$ & Repair \\
\hline & Mesentery & $1(2 \%)$ & Clip ligation \\
\hline & Multiple & $1(2 \%)$ & Laparotomy, Resection \& anastomosis \\
\hline \multirow{5}{*}{ Large Intestine } & Ascending & $1(2 \%)$ & Primary repair \\
\hline & Transverse & $2(4 \%)$ & Repair \\
\hline & Splenic flexure & $1(2 \%)$ & Primary repair \\
\hline & Descending & $2(4 \%)$ & Laparotomy \& colostomy \\
\hline & Sigmoid & $3(6 \%)$ & Laparotomy \& colostomy \\
\hline \multicolumn{2}{|c|}{$\begin{array}{l}\text { Diaphragm \& Large Intestine (splenic } \\
\text { Flexure) }\end{array}$} & $2(4 \%)$ & Repair, laparotomy \& colostomy \\
\hline \multicolumn{2}{|c|}{ Diaphragm \& spleen } & $1(2 \%)$ & Repair \& hand assist splenectomy \\
\hline \multicolumn{2}{|c|}{$\begin{array}{l}\text { Large intestine (rectum), ureter \& } \\
\text { urinary bladder }\end{array}$} & $1(2 \%)$ & $\begin{array}{c}\text { Laparotomy, repair \& ureter } \\
\text { reimplantation }\end{array}$ \\
\hline \multicolumn{2}{|c|}{$\begin{array}{l}\text { Large intestine (sigmoid) \& } \\
\text { retroperitoneal hematoma }\end{array}$} & $1(2 \%)$ & Laparotomy \& colostomy \\
\hline \multicolumn{2}{|c|}{ Diaphragm, liver \& kidney } & $1(2 \%)$ & Laparotomy, repair \& nephrectomy \\
\hline \multicolumn{2}{|c|}{$\begin{array}{l}\text { Small intestine (ileum), large intestine } \\
\text { (caecum) \& retroperitoneal hematoma }\end{array}$} & $1(2 \%)$ & $\begin{array}{l}\text { Laparotomy, repair \& right } \\
\text { hemicolectomy }\end{array}$ \\
\hline \multicolumn{2}{|c|}{$\begin{array}{l}\text { Small intestine (ileum) \& large } \\
\text { intestine (ascending) }\end{array}$} & $1(2 \%)$ & $\begin{array}{l}\text { Laparotomy, hemicolectomy\&ilio- } \\
\text { colic anastomosis }\end{array}$ \\
\hline \multicolumn{2}{|c|}{$\begin{array}{l}\text { Small intestine (ileum), large intestine } \\
\text { (sigmoid), urinary bladder \& } \\
\text { retroperitoneal hematoma }\end{array}$} & $1(2 \%)$ & $\begin{array}{l}\text { Laparotomy, primary repair \& } \\
\text { sigmoidal colostomy }\end{array}$ \\
\hline \multicolumn{2}{|c|}{$\begin{array}{l}\text { Small intestine (jejunum) and large } \\
\text { intestine (multiple) }\end{array}$} & $1(2 \%)$ & $\begin{array}{l}\text { Laparotomy, jejunal repair and } 2 \text { barrel } \\
\text { colostomy }\end{array}$ \\
\hline \multicolumn{2}{|c|}{$\begin{array}{l}\text { Stomach, liver, Small intestine (ileum) } \\
\text { \& large intestine (transverse) }\end{array}$} & $1(2 \%)$ & Laparotomy \& repair \\
\hline \multicolumn{2}{|c|}{ Stomach \& gallbladder } & $1(2 \%)$ & Cholecystectomy \& pyloric repair \\
\hline
\end{tabular}

In the post-operative period the mean first bowel motion (1.26 \pm 0.491$)$ days, mean first oral intake $(2.76 \pm 1.08)$ days, mean ICU stay $(2.04 \pm 1.19)$ days and the mean hospital stay $(5.94 \pm 2.70)$ days. The first bowel motion in post-operative period depend on procedure and affect in the first oral intake. Whatever oral intake delayed in bowel anastomosis (small \& large). In diagnostic laparoscopy return to bowel motion and oral intake (1-2 days) faster than laparotomy (2-4 days).The post-operative complications affect the stay in ICU and hospital. In our study male patient presented by gunshot underwent diagnostic laparoscopy revealed urinary bladder, right ureter and rectal tears. Convert to laparotomy with UB repair, RT ureter reimplantation and Hartman colostomy. Post-operative patient aggravated chest infection and pneumonia (5 days ICU stay) Seroma and wound infection appeared and Foleys catheter are left for 10 days (12 days hospital stay) (Table 7). 
Table (7): First bowel motion, oral intake, ICU stay and hospital stay

\begin{tabular}{|l|c|c|}
\hline Parameter Count & Mean & (Min- Max) \\
\hline First bowel motion & 1.26 & $(1-3)$ \\
\hline First oral intake & 2.76 & $(1-7)$ \\
\hline ICU stay (days) & 2.04 & $(1-5)$ \\
\hline Hospital Stay (days) & 5.94 & $(2-13)$ \\
\hline
\end{tabular}

Post-operative complications occur in 11 patients. Four patients $(8 \%)$ suffer from chest infection and pneumonia treated by broad spectrum antibiotics. three patients $(6 \%)$ post laparotomy; one of them aggravate respiratory failure and need mechanical ventilation and one patient $(2 \%)$ post laparoscopy. Three patients $(6 \%)$ suffered from wound infection treated by antibiotics according to culture and sensitivity and regular wound dressing. two patients $(4 \%)$ post laparotomy and one patient (2\%) post laparoscopy. One patient (2\%) complicated by biliary leakage post laparoscopic hepatic tear repair undergo ERCP which find CBD injure that need biliary stent. Another patient $(2 \%)$ after laparoscopic diaphragmatic tear repair complicated by intra-abdominal collection and fever undergo another look diagnostic laparoscopy and find transverse colon and stomach missed tears and repaired laparoscopy. One patient (2\%) complicated by fecal fistula post laparoscopic ascending colon tear repair undergoing laparotomy and ileostomy. Spontaneous closure of the fistula after one month.

A female patient presented by lower abdominal stab wound with severe hypotension. After resuscitation diagnostic laparoscopy showed uterine tear with uncontrolled bleeding. Blood transfusion and laparotomy done for bleeding control. Post-operative she had DIC and fresh frozen plasma was given (Table 8).

Table (8): Post-operative Complications

\begin{tabular}{|l|c|c|c|}
\hline Parameters & Frequency & Percent & Management \\
\hline Pneumonia & 3 & $6 \%$ & Antibiotics \\
\hline $\begin{array}{l}\text { Pneumonia and } \\
\text { respiratory failure type } \\
\mathbf{2}\end{array}$ & 1 & $2 \%$ & Mechanical ventilation \\
\hline DIC & 1 & $2 \%$ & Fresh frozen plasma \\
\hline Fecal fistula & 1 & $2 \%$ & Laparotomy \& ileostomy \\
\hline Wound infection & 3 & $6 \%$ & Dressing \& antibiotics \\
\hline Biliary leak & 1 & $2 \%$ & ERCP \& stent \\
\hline Missed injury & 1 & $2 \%$ & Laparotomy \& repair \\
\hline
\end{tabular}

The mean time to return to daily activity was $5.98 \pm 2.17$ days and the mean time to return to work was $18.60 \pm 6.73$ days. Patients underwent laparotomy delayed in return to daily activity (8-9 days) and to work (12-24 days) due to time of operation, length of incision and occurrence of complication and depend on age, BMI, power of healing and intraoperative technique (Table 9). 
Table (9): Time to return to daily activity and work

\begin{tabular}{|l|c|c|}
\hline Time Count & Mean & (Min-Max) \\
\hline Time to return to daily activity & 5.98 & $(2-12)$ \\
\hline Time to return to work & 18.60 & $(4-28)$ \\
\hline
\end{tabular}

Mortality occurred in 6 cases (mortality rate $12 \%$ ). The causes of death were Chest infection and pneumonia in 2 cases. Low saturation and ventilation in 1 case. Septic shock in one case. Hypovolumic shock in one case. DIC in one case (Table 10).

Table (10): Mortality

\begin{tabular}{|c|c|c|c|}
\hline Count & & Frequency & Percent \\
\hline \multirow{2}{*}{ Mortality } & Yes & 6 & $12 \%$ \\
\cline { 2 - 4 } & No & 44 & $88 \%$ \\
\hline
\end{tabular}

\section{DISCUSSION}

The application of laparoscopy has increased considerably with technical advances and constantly increasing experience with its use in the management of acute surgical cases including trauma surgery. New algorithms have been developed by many trauma centers worldwide for the management of BT and PT to aid the fast and effective diagnosis of visceral injuries (Uranüs and Dorr, 2010). Ramos et al. (2018) performed laparoscopic evaluation hemodynamically stable patients. The initial HR was 99.00 (78-120) and the initial BP was 135.00 (110-145). In our study, the initial HR was 98.56 (70-160) and initial BP was 107.00 (80-140).

In our study, we performed a laparoscopic evaluation of 50 patients most of them due to penetrating trauma. Similar results were obtained by Ramos et al. (2018); but Kyoung et al. (2015) perform a laparoscopic evaluation of blunt trauma $(65 \%)$.
There were no false-negative investigations. The use of diagnostic laparoscopy in abdominal trauma was useful to decrease the rate of negative laparotomy (Ozkan et al., 2016).

The usual diagnostic procedures, diagnostic peritoneal lavage, sonography, and even CT, all have their strengths and weaknesses, and none of them were $100 \%$ reliable. For this reason, exploratory laparotomy was performed in the case of stab wounds, but with a high morbidity percentage that reached up to $40 \%$. Therefore, the main benefits of laparoscopy are that it can reduce the rate of nontherapeutic and negative laparotomies, identify diaphragmatic injuries accurately, and even, in some cases, provide a therapeutic option (Uranüs and Dorr, 2010).

In our experience, the indications of diagnostic laparoscopy in $78 \%$ were radiological finding, $18 \%$ penetrating wounds (gunshot and stab) to abdominal wall, while $4 \%$ presented after RTA with 
negative radiology under observation noticed decrease hemoglobin level $(7 \mathrm{~g} / \mathrm{dl})$ and hypotension $(90 / 60 \mathrm{mmHg})$ with tachycardia (100-110 beat/min).

Kyoung et al. (2015) recorded that the mean operative time for laparoscopy 91.20 (57-125) and for laparotomy 97.20 (70-140). In our study, we recorded that the mean operative time for laparoscopy was 59.09 (30-120) and for laparotomy was 95.62 (60-150).

In the largest study on laparoscopy in PT, it was reported that a multicenter retrospective study of 510 hemodynamically stable patients who underwent DL for PT. The inclusion criterion for the study was a hemodynamically stable patient who had penetration of the anterior fascia by a stab wound or a gunshot wound with a possible intraperitoneal injury. Negative or nontherapeutic laparotomy was avoided in $59.4 \%$ of patients (Ozkan et al., 2016).

In our experience of PT, laparoscopy was beneficial especially in hemodynamic stable patients. The results of our analysis demonstrated that the use of laparoscopy to evaluate 40 penetrating abdominal trauma patients was able to exclude significant intra-abdominal injuries, and $12.5 \%$ of penetrating abdominal trauma patients avoided undergoing a nontherapeutic laparotomy. Patients with significant intra-abdominal injuries, use of laparoscopic-based operations also had a high therapeutic success rate (45\%), primarily for repairs to the liver, diaphragm, mesentery, bowel and hand assisted splenectomy. Conversion to laparotomy was performed in 17 patients because of large splenic lacerations, descending colon tears, small bowel injuries required resection and anastomosis.

A previous study by Shah et al. (2011) showed that laparoscopy reduced the nondiagnostic laparotomy rate and was effective for the treatment of patients with blunt abdominal trauma and hemoperitoneum, with an overall failure rate of 4\%. Marwan et al. (2010) also reported similar results in pediatric patients with blunt abdominal trauma and concluded that laparoscopy is underutilized in cases of pediatric abdominal trauma.

In our experience of BT (Blunt Truma), laparoscopy was beneficial especially in hemodynamic stable patients. The results of our analysis demonstrated that the use of laparoscopy to evaluate 10 blunt abdominal trauma patients was able to exclude significant intra-abdominal injuries, and approximately $20 \%$ of blunt abdominal trauma patients avoided undergoing a nontherapeutic laparotomy. Use of laparoscopic-based operations also had a high therapeutic success rate $(70 \%)$, primarily for repairs to the liver, mesentery, diaphragm, bowel and hand assisted splenectomy. Conversion to laparotomy was performed in one patient because descending colon tear need Hartman colostomy.

A 10-year review of laparoscopic intervention from the University of Tennessee showed that the main utility of minimally invasive techniques was as usage of laparoscopy in management of abdominal trauma was effective to avoid negative laparotomy findings. Although some minor injuries were repaired laparoscopically, they were limited to 
diaphragm repair, repair of serosal tears and coagulation of omental hemorrhage. Nevertheless, a review of the published literature shows an increasing number of case reports showing successful therapeutic interventions in abdominal trauma. This trend will continue to grow as surgeons' comfort with minimally invasive techniques improves and technology becomes more convenient and advanced (Mohamed et al., 2015).

In our experience, the use of laparoscopy as a diagnostic and therapeutic tool lead to avoidance of an open surgery in more than $64 \%$ of patients. Negative and nontherapeutic laparoscopies were performed in $14 \%$ patients and therapeutic laparoscopy was performed in $50 \%$ patients: $16 \%$ patients hand assisted splenectomy, $10 \%$ patients need repair of liver tears, $6 \%$ patients need diaphragmatic tear repair, $14 \%$ patients need primary repair for bowel and 2 patients need stomach repair. However, conversion to laparotomy was needed in more than $30 \%$. Multiple organ injuries (16\%), colostomy for descending and sigmoid colonic tears (10\%), resection anastomosis for multiple small bowel injuries (2\%), and repair for uterine injuries (2\%).

Although the primary goal of laparoscopy in trauma is to make a diagnosis and/or exclude injury. It may also serve as a therapeutic tool in patients requiring intervention. We found that almost $64 \%$ of the patients requiring surgical therapy were successfully treated laparoscopically. These results were higher than previously reported rates of therapeutic laparoscopy, ranging from $8 \%$ to $50 \%$. With increasing surgeon expertise, improved equipment, and enhanced technology. These rates are likely to continue to climb (Kawahara et al., 2009).

Trauma laparotomy remains the gold standard for the evaluation of intraabdominal injury. However, complications following negative or nontherapeutic laparotomy can be as high as $20 \%$ (Shan et al., 2012). Consequently, it is advantageous to avoid a negative laparotomy, provided that a reliable and accurate alternative diagnostic procedure is available. Mohamed et al. (2015) laparoscopy resulted in sensitivity for abdominal injury exceeding $90 \%$, with a specificity of $100 \%$. Furthermore, it proved to be a safe modality without direct operative or postoperative morbidity. In our study, laparoscopy prevented laparotomies in $64 \%$ of patients.

The primary limitation of laparoscopic intervention is the poor visibility conferred by excessively edematous bowel or uncontrolled active bleeding at presentation. These are the major motivations for conversion to open laparotomy. Edema of the bowel is a time dependent process. Thus, patients presenting shortly after the traumatic event are more easily managed through laparoscopy, whereas lengthier time intervals usually portend severe intestinal edema. Not only is the laparoscopic window obscured by edematous bowel, but traction injury is more likely to occur during manipulation (Di Saverio et al., 2014).

Another cause of open conversion is the spillage of large-sized particulates that cannot be aspirated via the usual mode of 
endo-suction. However, we were able to achieve complete evacuation in this event by direct insertion of a silastic tube through a $12-\mathrm{mm}$ port. Subsequently, our fears of postoperative intra-abdominal abscess never materialized. A fair number of our open conversions stemmed from trial-and-error in early experience, contributing to an open conversion rate of $36 \%$. With more experience, these conversions very well could have been avoided (Di Saverio et al., 2014).

Kyoung et al. (2015) recorded that hospital stay post laparoscopy (9-12 days) shorter than post laparotomy (17-25 days). In our study, we recorded that hospital stay post laparoscopy (2-5 days) shorter than post laparotomy (10-14 days) and hospital stay post penetrating trauma shorter than blunt trauma.

Potential risks when trauma patients undergo laparoscopy include air embolism, elevation of intracerebral pressure with head injuries, and tension pneumothorax when the diaphragm is injured. Small numbers of such complications were reported in the 1990s, and they now seem to be preventable if suitable measures are adopted (Mohamed et al., 2015).

The complications associated with laparoscopy in trauma patients included tension pneumothorax, air embolism, and intracranial hypertension. Lim et al. (2011) noted that the potential of gas embolism in patients with intraabdominal venous injuries such as liver lacerations is of concern when performing laparoscopy; however, none of our patients in the laparoscopic group developed clinical signs or symptoms of a gas embolism.
In our study, the hospital stay and rate of postoperative complications were high in patients with BT than PT. In cases without conversion to laparotomy, we found one case with chest infection and one patient with wound infection. Conversion to laparotomy, we found two patients with wound infection and three patients with chest infection. However, overall, the rate of hospital stay and postoperative complications was low in comparison with patients managed by laparotomy.

Traumatic abdominal injury is traditionally subject to open exploration and remains a challenge for the general surgeon, especially with respect to controlling wound-related complications. Wound complications still play a major role in lengthy hospital stays and may lead to other delayed morbidities. Our aim was to extend the benefits of minimally invasive surgery to traumatic abdominal injury, thereby decreasing postoperative complications. Indeed, wound infections requiring delayed closure following open laparotomy. By comparison, none of the patients undergoing laparoscopy suffered a wound complication.

In our study, mortality occurred in $12 \%$ of cases. The causes of death are Chest infection and pneumonia in $4 \%$ cases. Low saturation and ventilation in $2 \%$ of cases. Septic shock in $2 \%$ of cases Hypovolumic shock in $2 \%$ of cases. DIC in $2 \%$ of cases.

The potential for a missed hollow viscous injury after diagnostic laparoscopy exists and may have devastating consequences. In the current study, $2 \%$ patients had a missed common bile duct injury that required 
reintervention. These results were comparable with Mohamed et al. (2015) who showed that laparoscopy yielded a sensitivity of $92 \%$ and a specificity of $100 \%$ in detecting injuries in patients who suffered from blunt abdominal injury, while also avoiding $50 \%$ of laparotomies in that same population. Earlier reports commonly cited a high missed injury rate as a result of using diagnostic laparoscopy to screen patients with potential abdominal injuries. Kawahara et al. (2009) used a systematic approach to laparoscopic abdominal exploration, which resulted in no missed injuries.

When first used for trauma, laparoscopy resulted in high rates of missed injury (41-77\%), generating considerable criticism. One of the most serious concerns was its lack of consistency in detecting small bowel damage which is the main reason surgeons still hesitate today; but because these studies involved both prospective and retrospective analyses and procedures were not standardized, the data are difficult to interpret. In addition, the learning curve of laparoscopic surgery was ignored in early evaluations, and subjective preferences do seem to drive decisions during laparoscopy.

One prior report underscored the reliability of laparoscopy as a tool for evaluating traumatic injuries, when used for specific indications and with appropriate technique. Kawahara et al. (2009) devised systematic laparoscopic explorations of the abdomen that resulted in no missed injuries. In accordance with the method of Choi, we found it relatively easy to effectively inspect all abdominal organs, without missing an injury.
The keys to successfully diagnosing and treating significant intra-abdominal injuries laparoscopically include a systemic exploration to avoid missed injuries using appropriate changes in position of the patient, careful planning of port placement, technical ability in advanced laparoscopic procedures, and experience of surgeons gained by treating stab wounds. The value of a standard examination system for laparoscopy to avoid missed injuries has been reported by Kawahara et al. (2009) for stab wounds, and also proved to be effective for blunt trauma in this study. We illustrated in our previous report that a surgeon can perform a laparoscopy safely for patients with stab wounds if he or she has performed at least 20 laparoscopic procedures for acute care surgery monthly.

Based on the results of this report, we believe that a surgeon can perform an error-free laparoscopy for patients with blunt abdominal trauma if he or she has performed at least 5 laparoscopic operations for abdominal stab wounds. Advanced laparoscopic techniques such as intracorporeal suturing offer the opportunity to increase the success rate of therapeutic laparoscopy in the treatment of complex injuries.

Minimally invasive surgery has become a useful tool in the management of trauma. Laparoscopy can detect and repair injuries to the hollow viscus and diaphragm and exclude the risks of nontherapeutic laparotomy. Further advantages are reduced morbidity, shortened hospital stay, and lower cost. In the future, there may be exciting advancements for this field of surgery 
through innovative developments (Uranüs et al., 2010).

\section{CONCLUSION}

Although we disclose that laparoscopy gradually has being accepted as a diagnostic and/or treatment modality for penetrating abdominal injuries in patients that are hemodynamically stable. The relative rates of morbidity/mortality, postoperative complications, and missed injury are low and compare favorably with an open approach. However, laparoscopic surgery can be performed safely whether injuries are blunt or penetrating, given hemodynamic stability and proper technique. Patients may thus benefit from the shorter hospital stays, greater postoperative comfort (less pain), quicker recoveries, and low morbidity/mortality rates that laparoscopy affords.

Laparoscopy is feasible and safe for the diagnosis and treatment of hemodynamically stable patients with blunt and penetrating abdominal trauma. It can reduce the laparotomy rate and provide the advantages of minimally invasive surgery for patients with significant intra-abdominal injuries in terms of shorter hospital stay.

Minimally invasive surgery has become a useful tool in the management of trauma. Laparoscopy can detect and repair injuries to the hollow viscus and diaphragm and exclude the risks of nontherapeutic laparotomy. Further advantages are reduced morbidity, shortened hospital stay, and lower cost. In the future, there may be exciting advancements for this field of surgery through innovative developments.

\section{REFERENCES}

1. Ball C, Karmali S and Rajani R. (2009): An evolution in progress Injury .World Journal of Emergency Surgery. 40(1):7.

2. Bendinelli $C$ and Balogh $Z$ (2012): Laparoscopy in Trauma Patients. Advances in Laparoscopic Surgery, 1: 43-47.

3. Como JJ, Bokhari F, Chiu WC, Duane TM, Holevar MR, Tandoh MA, Ivatury RR and Scalea TM. (2010): Practice management guidelines for selective nonoperative management of penetrating abdominal trauma. J Trauma, 68:721-33.

4. Deunk J, Brink M, Dekker HM, Kool DR, Blickman JG, van Vugt AB and Edwards MJ. (2010): Predicators for the selection of patients for abdominal CT after blunt trauma: a proposal diagnostic algorithm. Ann Surg., 251:512-520.

5. Di Saverio S, Bassi M, Smerieri N, Masetti M, Ferrara F, Fabbri C, Ansaloni L, Ghersi S, Serenari M, Coccolini F, Naidoo N. (2014): Diagnosis and treatment of perforated peptic ulcer.; 16(5):385-388.

6. Kawahara NT, Alster C, Fujimura I, Poggetti RS and Birolini D. (2009): Standard examination system for laparoscopy in penetrating abdominal trauma. J Trauma, 67:589-95.

7. Kyoung, Chirica M, de Chaisemartin C, Gornet JM, Munoz-Bongrand N, Halimi B. (2015): Caustic injuries of the upper digestive tract: a population observational study. Surg Endosc.; 26:214-221.

8. Lim K, Chung B, Kim $J$ and Kim S. (2015): Laparoscopic surgery in abdominal trauma. World Journal of Emergency Surgery, 10:16.

9. Mackersie RC. (2010): Pitfalls in the evaluation and resuscitation of the trauma patient. Emerg Med Clin N Am, 28: 2-27.

10. Marwan A, Harmon CM, Georgeson KE, Smith GF and Muensterer OJ. (2010): Use of laparoscopy in the management of pediatric abdominal trauma. J Trauma, 69:761-4. 
11. Mohamed M, Mansy $W$ and Zakaria $Y$. (2015): Use of laparoscopy in the management of abdominal trauma: a center experience. The Egyptian Journal of Surgery, 1, 34(1): 11

12. Neal MD, Sippey M, Gaines $B A$ and Hackam DJ. (2009): Presence of pneumomediastinum after blunt trauma in children: what does it really mean. Journal of Pediatric Surgery, 44(7):1322-7.

13. Ozkan OV, Justin V, Fingerhut $A$ and Uranues S. (2016): Laparoscopy in abdominal trauma. Current Trauma Reports, 2(4):238-46.

14. Ramos LP, Araújo RB, Castro M, Ramos MR and Iglesias AC. (2018): Hemodynamic evaluation of elderly patients during laparoscopic cholecystectomy. Revista do Colégio Brasileiro de Cirurgiões, 45(2):265275.
15. Shah SM, Shah KS, Joshi PK, Somani RB, Gohil VB and Dakhda SM. (2011): To study the incidence of organ damage and post-operative care in patients of blunt abdominal trauma with haemoperitoneum managed by laparoscopy. J Minim Access Surg., 7:169-172.

16. Shan B, Gerez J, Haedo $M$, Fuertes $M$, Theodoropoulou M, Buchfelder M, Losa M, Stalla GK, Arzt E \& Renner U (2012): RSUME is implicated in HIF-1-induced VEGFA production in pituitary tumour cells. EndocrineRelated Cancer 19 13-27.

17. Uranüs S and Dorr K. (2010): Laparoscopy in abdominal trauma. European Journal of Trauma and Emergency Surgery, 36(1):1924. 


\section{دور المنظار الجراحي في مناجزة إصابات البطن}

هارون علام، إبراهيم عبد الغفار إبراهيم، محمد مصطفى تاج الدين، أحمد عبد الثافي محمد

\section{قسم الجراحه العامة، كلية الطب، جامعة الأزهر}

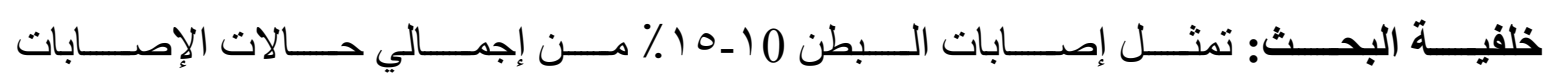

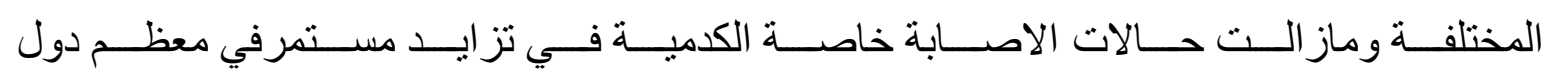

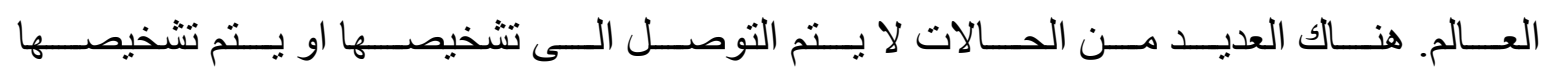

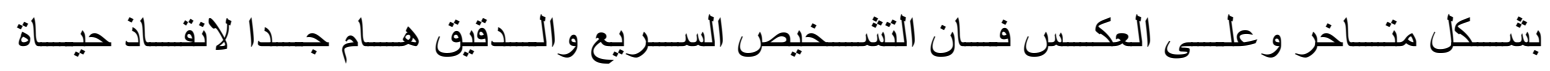
المريض.

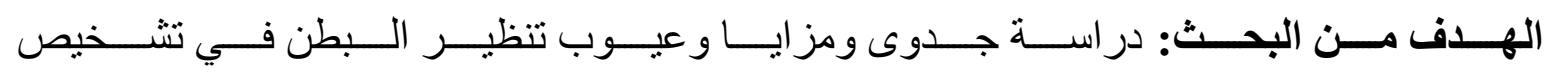
وعلاج الإصابات في البطن.

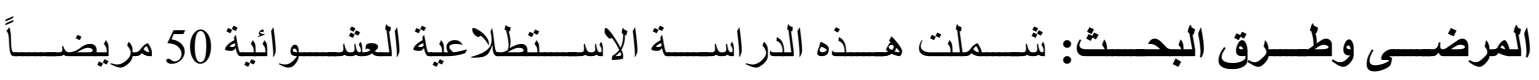

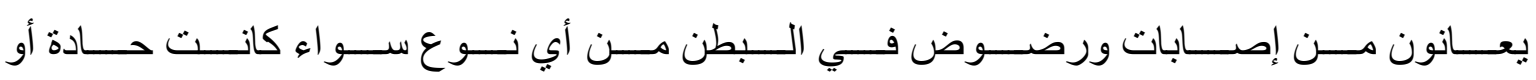

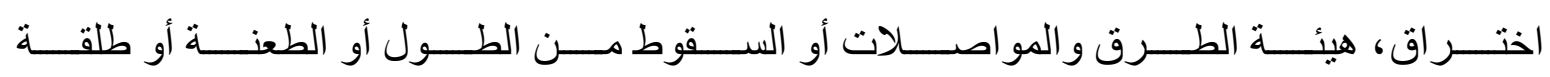

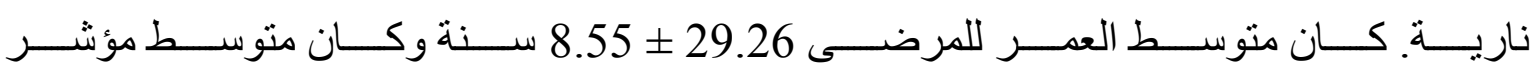

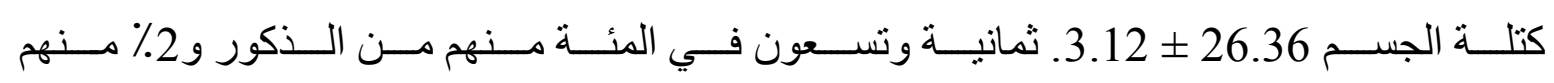
من الإناث.

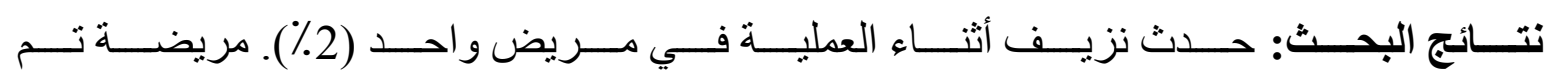

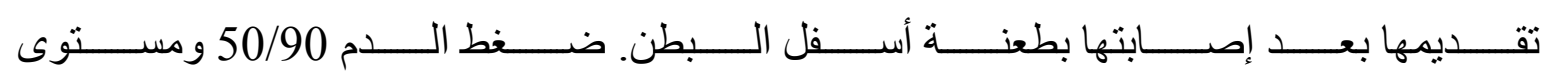

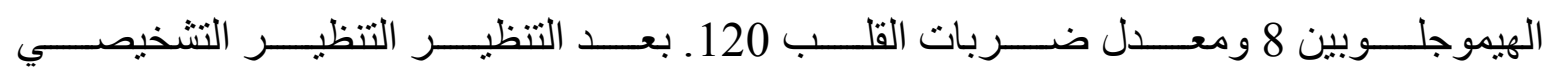

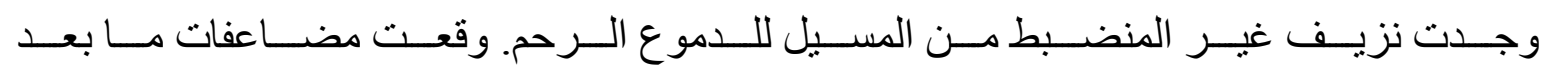

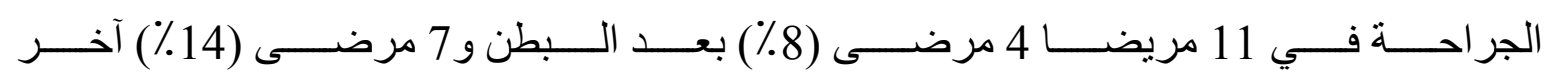

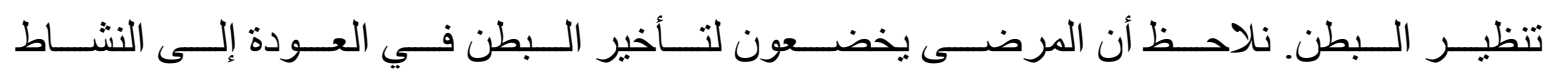

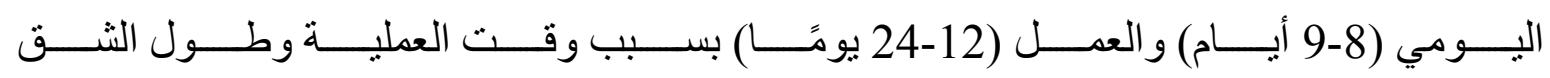

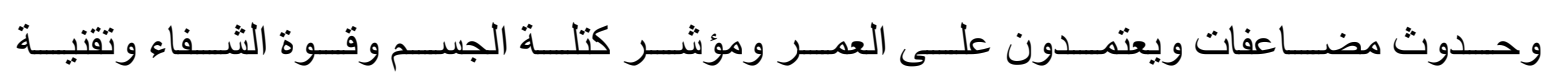

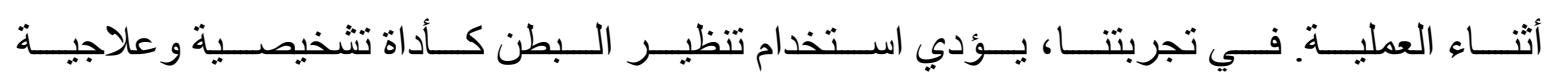




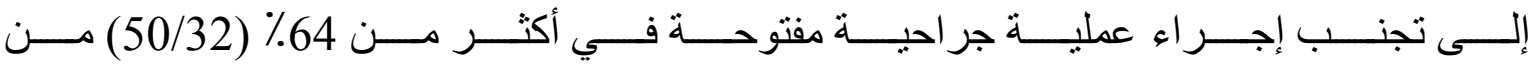

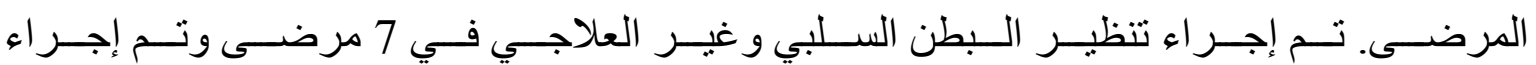

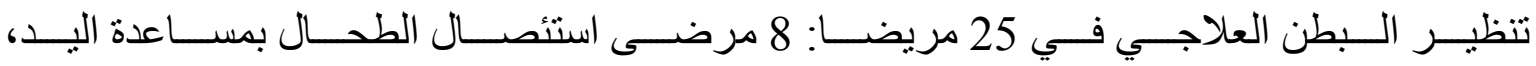

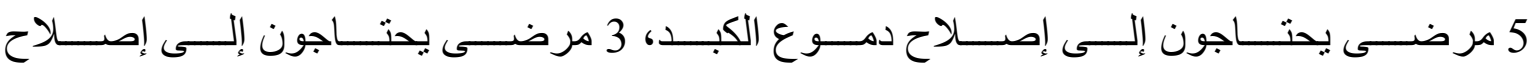

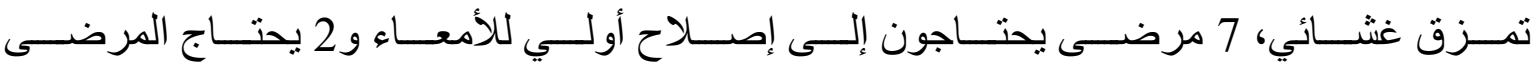

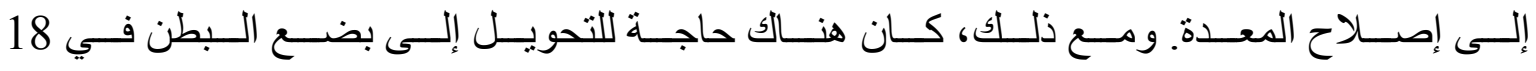

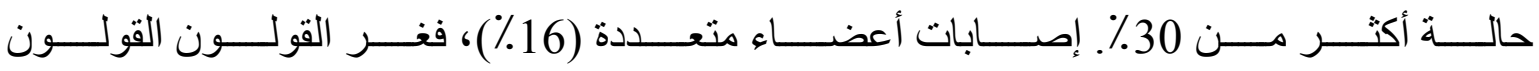

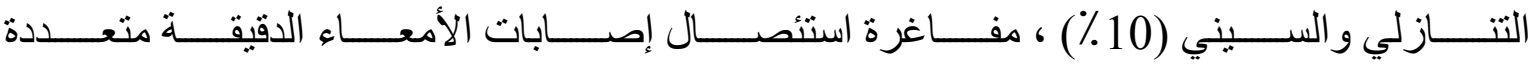

$$
\text { (2)، و إصلاح لإصابات الرحم (2). }
$$

الاســتنتاج: تشـــمل مفــاتيح تشــخيص و عــلاج الإصـــابات الكبيــرة داخــل الــبطن بالمنظـــار

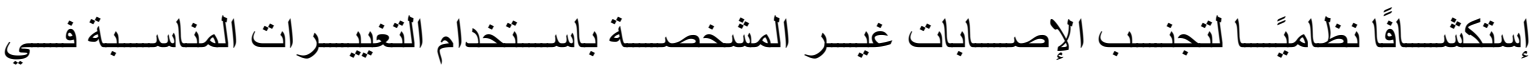

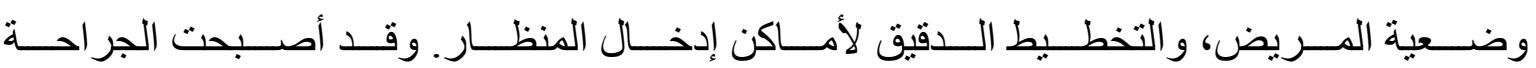

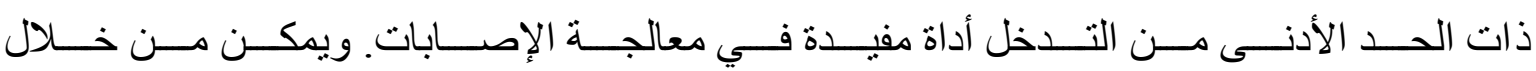

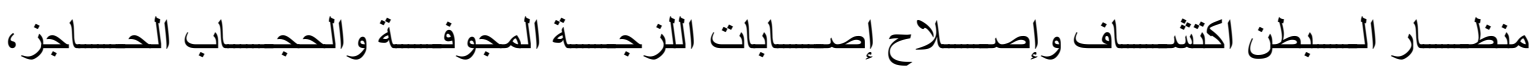

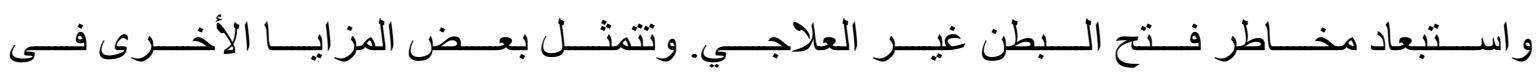

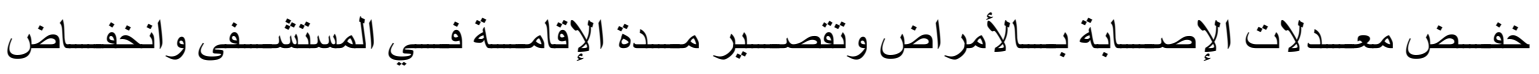

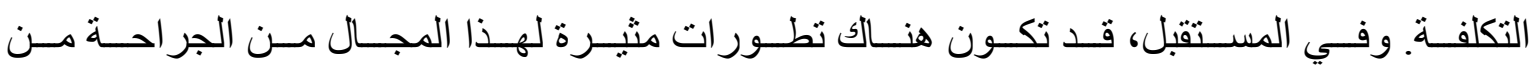

